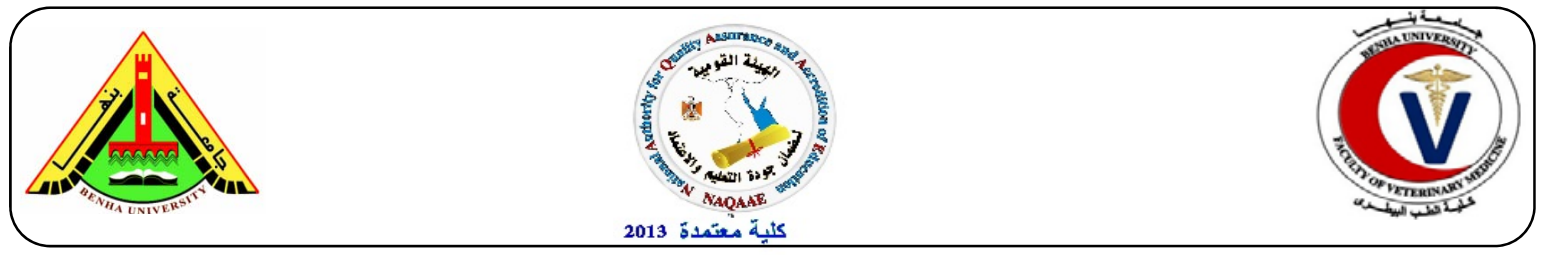

\title{
Detection of FMD virus antigens and antibodies using staph protein-a rapid agglutination test in comparison with the used traditional methods
}

\author{
Ekbal, M. Farouk ${ }^{1}$; Khodeir, M.H. ${ }^{1}$ and Hanaa, Abd Elazeiz ${ }^{\mathbf{2}}$ \\ ${ }^{1}$ Veterinary Serum and Vaccine Research Institute, Abbasia, Cairo, E.mail: svri@idsc.gov.eg \\ ${ }^{2}$ Central Laboratory for Evaluation of Veterinary Biologics, Abbasia, Cairo
}

\section{A B S T R A C T}

Considering rapid accurate detection of FMD virus antigens and antibodies is an essential corner stone in the epidemiological studies; Staphylococcal protein-A (SPA) was successfully prepared and used for application of rapid agglutination test (RAT) on both of processed infected tongue epithelium and infected cell culture fluid for detection of FMD virus antigens using reference viruses and anti-sera. It was found that the traditional virus neutralization test (VNT) consuming long time (18-24 hours) and RAT with the shortest time (2-5 minutes) were able to detect the antigens of FMDV type O; $A$ and $S A T_{2}$ with titer ranged from $\leq \log 10$ up to $7 \log 10 \mathrm{TCID}_{50} / \mathrm{ml}$. In addition, RAT carried on serum samples obtained from vaccinated animals revealed positive results with titers similar to those obtained by serum neutralization test (SNT) ranged from $\leq 2$ up to 256 for the three virus types with shorter time (2-5 minutes) than that consumed by SNT (18-24 hours). It was noticed that high antigen or antibody titers showed strong agglutination while weak agglutination was noticed with lower titers. So it could be concluded that the present work provides a rapid; sensitive and accurate test to detect FMDV antigens and antibodies as safe; easy to be used, highly sensitive, rapid field test, of low cost and having friendly environmental relationship.

Key word: Foot and mouth disease (FMD); Staph protein A (SPA); Rapid agglutination test (RAT).

(http://www.bvmj.bu.edu.eg)

(BVMJ-29(2): 129-135, 2015)

\section{INTRODUCTION}

$\mathrm{F}$ oot and mouth disease (FMD) is one of the most troubles viral diseases among livestock especially cloven footed animals of both wild and domestic animals like cattle, buffaloes, sheep, goats and pigs (OIE 1972 and Sharma 1981). It is caused by a filterable virus belongs to genus Aphthovirus, family Picornaviridae, as a non enveloped icosahedral RNA virus of positive sense, the virus has 7 serotypes that differ antigenically and immunologically with different subserotypes distributed world wide (Pereira 1977and Franki et al., 1991). The disease is still one of the most important infectious diseases that could not be neglected where it causes great economic losses among cloven hoofed animals. The disease became world wide in extent where major epizootics have developed in many parts of the world every few years (Anon, 1978). Regarding Egypt different types of FMD virus like $\mathrm{SAT}_{2}, \mathrm{O}$ and $\mathrm{A}$ were identified Type A and $\mathrm{SAT}_{2}$ were the main causes of outbreaks of 1953, 1958 and 1960 (Moussa et al, 1974; Daoud et al, 1988; ElNakashly et al, 1996; Farag et al 2004 and Abd El-Rahman et al, 2006).

Specific, rapid and sensitive serological tests are required for accurate diagnosis of FMD as an essential step in controlling the disease. Staphylococcal protein -A "SPA" is a protein bound to the cell wall of the pathogenic bacterium Staphylococcus aureus (S. aureus) binds to the Fc portion of most mammalian class $\mathrm{G}$ immunoglobulins. Therefore, this protein has a unique potential for making "universal" immunoassays (Aslam and Dent, 1998). 
Some strains of S-aureus synthesize protein - A, a group specific ligand which binds the Fc region of IgG from many species. It binds to human, mouse, rabbit, cat, cow, dog, goat, Guinea pig, horse and sheep IgG but not bind to chicken (-) and hamster $( \pm)$ IgG (Alan and Rabinthorpe, 1996). SPA has increasing importance as a tool in both quantitative and qualitative immunological techniques. SPA remains markedly stable on exposure to high temperatures, low $\mathrm{pH}$ and denaturizing agents (Montassier et al, 1994). SPA was used to develop a coagulation "COA" test for the detection and typing of FMDV. Its simplicity and rapidity of performance and its low cost, has a great potential for direct detection and identification of FMDV as screening strategy at FMDV outbreaks (Montassier et al, 1994 and Saad et al, 2000).

The present work aims to provide a rapid and accurate method for detection of FMD antigens and antibodies as a golden goal aid to reach more fast diagnosis than that carried out by traditional methods which are time consuming; require more complicated steps with higher cost. Such aim could be established through application of rapid agglutination test using SPA as non-specific anti-specie.

\section{MATERIAL AND METHODS}

\subsection{FMDV serotypes:}

Local foot and mouth disease (FMD) viruses type $O, A$ and SAT2, were kindly provided by Veterinary Serum and Vaccine Research Institute (VSVRI) - Abasia Cairo. These viruses were propagated in BHK-21 cell culture to subject for detection by rapid agglutination test using SPA and virus neutralization test using specific reference anti-sera.

\subsection{Samples from infected animals:}

Tongue epithelium samples were obtained from experimentally infected cattle during the applied challenge test during the evaluation process of trivalent FMD vaccine by the Central Laboratory for
Evaluation of Veterinary Biologics. These samples were processed and propagated 3 times in BHK21 cell culture and used in RAT.

\subsection{Cell culture:}

Baby hamster kidney $\left(\mathrm{BHK}_{21}\right)$ cell culture was supplied by VSVRI and used for virus propagation; virus neutralization and serum neutralization test.

\subsection{Serum samples:}

Fifty serum samples were obtained from vaccinated cattle with trivalent $F M D$ vaccine in addition to reference anti-FMD sera (type O; A and SAT2) were supplied by the Department of Foot and Mouth Disease Research, VSVRI. These sera were subjected for detection of FMD antibodies by rapid agglutination test using $S P A$ and SNT using specific FMD type $O, A$ and SAT2.

\subsection{Bacterial strain:}

Cowan-1 strain of S.aureus was supplied by Prof. Dr. Saad, M.A.M (Animal Reproduction Research Institute; Al-haram Giza) for preparation of SPA according to Kessler (1975) and Sting et al (1990).

\subsection{Preparation of SPA suspension according to Kessler (1975):}

Cowan 1 strain of $S$. aureus was cultivated in one liter of 199 medium supplemented with $0.5 \%$ lacto-albumin hydrolysate and $0.5 \%$ yeast extract. The inoculated medium was dispended in bottle was incubated at $37 \mathrm{C}^{0}$ for 24 hours with gentle shaking every 3 hrs. Growing bacteria were collected by centrifugation at $800 \mathrm{xG}$ for 10 minutes and washed twice with PBS at PH 7.2 containing $0.05 \%(\mathrm{w} / \mathrm{v})$ sodium azide (PBS azide). Bacteria were resuspended to approximately $10 \%(\mathrm{w} / \mathrm{v})$ concentration in PBS- azide. Fixed bacteria were then washed once with PBS azide without formalin and re-suspended again into the same buffer to $10 \%$ concentration. The suspended bacteria were killed by heating at $80 \mathrm{C}^{0}$ with rapid swirling in water bath for 5 min followed by rapid cooling in PBS azide 
and finally made to $10 \%$ suspension. The SPA suspension could be stored at $4^{0} \mathrm{C}$ where it was stable for at least 4 months. Before use the SPA suspension should be treated with NP-40 (0.5\%) in Net Buffer PH 8.0 ; for $20 \mathrm{~min}$ at room temperature. The treated SPA suspension was then washed once with $0.05 \%$ NP-40 in Net buffer and finally re-suspend to the original concentration ( $10 \%$ suspension) in the later buffer.

\subsection{Virus neutralization test (VNT):}

It was carried out according to OIE (2000) using the microtiter method to identify the obtained FMDV isolate.

\subsection{Serum neutralization test (SNT):}

It was carried out on serum samples obtained from the 100 cattle included in the present work before and post vaccination on different periods. The test was carried out according to Ferreira (1976).

\subsection{Rapid agglutination test (RAT):}

Rapid agglutination test was carried out on FMD virus type $O ; A$ and SAT2 obtained from infected BHK21 cell culture for detection of the virus antigens using specific anti-sera and on vaccinated cattle sera and reference FMD anti-sera using the prepared SPA. The test was carried out according to Montassier et al (1994).

\section{RESULTS:}

SPA was prepared and used for application of RAT on processed infected tongue epithelium and FMD virus infected cell culture. It was found that both of RAT and traditional VNT were able to detect the antigens of FMDV type $O$; $A$ and SAT with titer ranged from $\leq \log 10$ up to $7 \log 10$ TCID $50 / \mathrm{ml}$ with faster results obtained by RAT within 2-5 minutes while VNT needs 18-24 hors (table-1). RAT carried out on serum samples from vaccinated animals revealed positive results with titers similar to those obtained by SNT [ $2 \leq$ up to 256] for the three virus types as tabulated in table (2) (within 2-5 minutes for RAT and 18-24 hours for $S N T$ ). It was noticed that the strength of agglutination was strong with high titers of virus antigen or antibodies and weak with lower titers as demonstrated in photo (1\&2).

Table (1): Detection of FMD viruses in infected cell culture and processed tongue epithelium fluids

\begin{tabular}{|c|c|c|c|c|}
\hline \multirow[t]{2}{*}{ Applied test } & \multicolumn{4}{|c|}{ Detected FMD virus titer } \\
\hline & Type O & Type A & Type SAT2 & Required time \\
\hline Virus neutralization & From lc & up to 71 & $\mathrm{TCID}_{50} / \mathrm{ml}$ & 18-24 hours \\
\hline Agglutination test & & & & 2-5 minutes \\
\hline
\end{tabular}

Virus neutralization test was carried out using specific anti-sera in BHK21 cell culture. Agglutination test was carried out using specific anti-sera and SPA.

Table (2): Detection of FMD antibodies

\begin{tabular}{|c|c|c|c|c|}
\hline \multirow[t]{2}{*}{ Applied test } & \multicolumn{4}{|c|}{ Detected FMD antibody titer } \\
\hline & Type O & Type A & Type SAT2 & Required time \\
\hline Serum neutralization test & \multirow{2}{*}{\multicolumn{3}{|c|}{ From $2 \leq$ up to 256}} & 18-24 hours \\
\hline Agglutination test & & & & 2-5 minutes \\
\hline
\end{tabular}




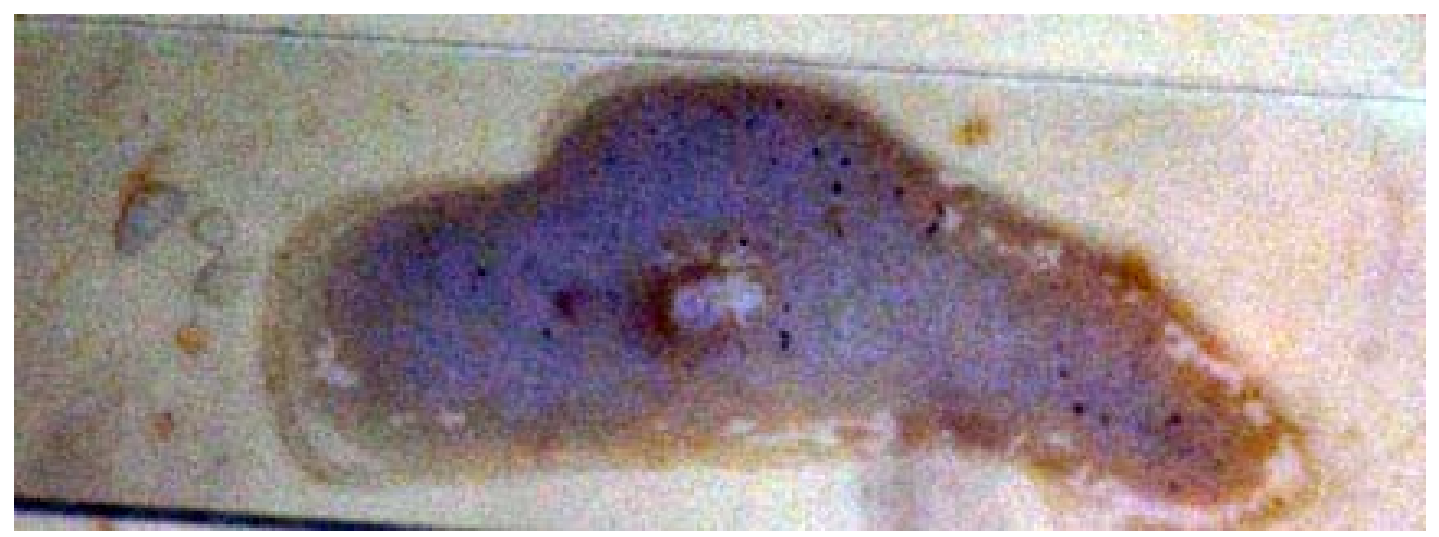

Photo (1): Strong agglutination reaction

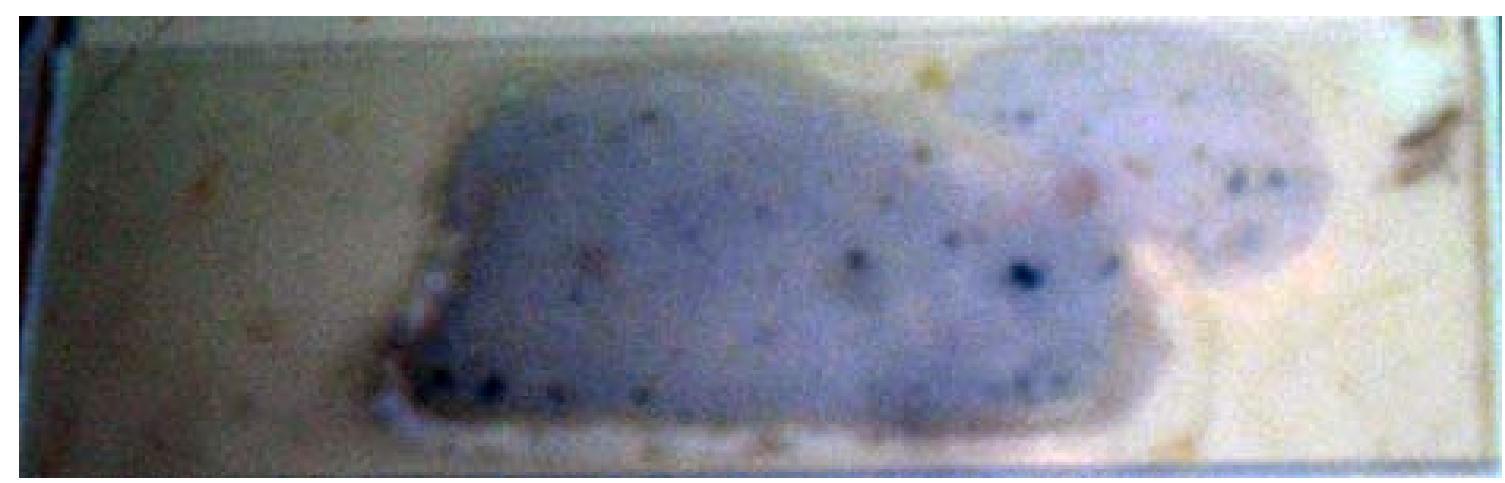

Photo (2): Weak agglutination reaction

\section{DISCUSSION:}

It is a golden goal to reach rapid; specific and accurate diagnosis of FMD through the detection of the virus antigens and antibodies. Successful preparation of SPA was confirmed through the present work and used for application of rapid agglutination test (RAT) on both of processed infected tongue epithelium and infected cell culture fluid for detection of $F M D$ virus antigens in comparison with the traditional VNT showing that both tests were able to detect the antigens of FMDV type $O$; $A$ and $S A T_{2}$ with titer ranged from $\leq$ $\log 10$ up to $7 \log 10$ TCID $50 / m l$ but RAT showed faster results within 2-5 minutes while VNT needs 18-24 hors. In addition, RAT carried on serum samples obtained from vaccinated animals revealed positive results with titers similar to those obtained by serum neutralization test (SNT) ranged from $\leq 2$ up to 256 for the three virus types as tabulated in table (2) with shorter time (2-
5 minutes) than that consumed by SNT (1824 hours). It was noticed that the strength of agglutination was strong with high titers of virus antigen or antibodies and weak with lower titers as demonstrated in photo (1\&2). These findings could be explained depending on the fact that the reactivity of immunoglobulin-binding proteins for immunoglobulin proteins (Igs) of mammalian species is well known. These proteins are staphylococcal protein-A (SPA), streptococcal protein G (SPG), staph protein AG-horse radish peroxidase (SPAG-HRP). These conjugates have a potential use in epidemiological surveys of zoonotic infections (Angel Alberto Justiz Vaillant, 2013).

Hanaa et al (2011) demonstrated that due to the nature of SPA to bind with FC portion of the most mammalian immune-globulins class G. Therefore, this protein has a good ability to react with wide range of animal species mainly when anti-immunoglobulin not available as in case of camel IgG. 
Similar applications showed typical macroscopic patterns of positive and negative coagulation reactions obtained by interaction of the homogenate supernatants of the skin biopsies $(100 \%)$ with positive and negative sera of rabbits against lumpy skin disease virus. Staphylococcal protein A Coagulation was rapid (Carried out in 5$10 \mathrm{~min}$ ) accurate, sensitive, specific and economic and not require special equipment (Iman and Saad, 2007). Iman et al (2011) aggregated Rhabdoviral particles coated with the specific antibody were observed in addition to their attachment to the surface staphylococcus aurous protein A.

In addition, Sigma showed that protein - A is capable of binding to the Fc portion of immune globulins, especially IgGs, from large number of species. Protein- $\mathrm{A}$ is a highly stable cell surface receptor produced by several stations of Staphylococcus aureus. Protein A may be conjugated with various receptor molecules, including fluorescent isothiocyanate (FITC), enzyme marker, (peroxidase without affecting the antibody binding site on the molecule.

It was suggested that the discovery of protein $\mathrm{A}$, and subsequently protein $\mathrm{G}$, immune- affinity Chromatography has ground in popularity and is now the standard methodology for the purification of antibodies which many be implemented for selection of different application such as immunodiagnostics (Darcy et al., 2011) It was concluded that Staphylococcal protein-A "SPA" has increasing importance as a tool in both quantitative and qualitative immunological techniques. Montassier et al, (1994) developed a coagulation "COA" test for the detection and typing of foot and mouth disease virus FMDV depending on its simplicity; rapidity of performance and its low cost, having a great potential for direct detection and identification of FMDV as screening strategy at FMDV outbreaks in agreement with Montassier et al (1994) and Saad et al (2000). In addition, Omnia et al (2015) concluded that SPA is safe; easy to be used, high stable, highly sensitive, can be used as rapid field test, of low cost having friendly environmental relationship.

Depending on the obtained results and in agreement with Nielsen et al. (2004); it could be concluded that Staphylocoocus aureus Cowan strain is among a group of bacteria that produce protein with capacity attach to immune globulin molecules of various species aiding to rapid detection of bacterial and viral antigens and antibodies in order to reach rapid control of FMD facing different live stocks.

\section{REFERENCES}

Abd El-Rahman, A.O., Farag, M.A., Samira El-Kilany, Ali, S.M. and Manal, Abo El-Yazeid 2006. Isolation and identification of serotype $\mathrm{O}$ of foot and mouth disease virus from imported bulls and its correlation to the current used vaccine strain O1/3/1993. $3^{\text {rd }}$. Intern. Conf. Vet. Res. Div. NRC, Cairo, Egypt, pp. 91100.

Alan, J. and Rabinthorpe 1996: Coupling antibodies to fluorochromes enzymes and biotin preparation of S- aureus adsorbent Immunochem in practices $3^{\text {rd }} \mathrm{ED}$, pp. 277-279, 249-251

Angel Alberto Justiz-Vaillant 2013: Preparation of universal peroxidase labeled bacterial protein conjugates and separation properties. J. Chromatograph separate technique 4:6

Anon 1978. History of foot and mouth disease Vet. Rec. 102:184-185

Aslam, M. and Dent, A. 1998. Bioconjugation protein coupling techniques for the biochemical sciences Macmillan. Ref. Ltd. U.K.

Daoud, A.M., Abd El-Rahman, A.O., ElBakry, M., Metwaly, N., ElMekkaawi, M. and Samira El-Kilany 1988. Strains of Foot and Mouth disease virus recovered from 1987 outbreak in Egypt. J. Egypt. Vet. Med. Ass., 48(1):63-71. 
Darcy, E., Leomard, P., Fitzgerald, J. Damaher, M., and Kemmedy, R. 2011. Purification of antibodies using affinity chromatography J. Clin. Microbiol. 49(2):638-646

El-Nakashly, S., Abou Zaid, A.A., Samira El-Kilany and Abd El-Aty, M.M. 1996. Isolation and identification of foot and mouth diseases virus during an outbreak in 1993 in Egypt $7^{\text {th }}$ Sci. Conf. Fac. Vet. Med. Assiut Univ. pp. 679-687.

Farag, M.A., Halima, M. El-Watany, and Abeer, A. Talaat 2004. Detection of FMD virus using a dot immunoblot and RT-PCR from field samples $1^{\text {st }}$. Sci. Conf. Fac. Vet. Med. Moshtohor, 1/4:89-99.

Ferreira, M.E. 1976. Prubade microneutralization poraestudios. Cent. Paname. Fiebre. Aflosa, 2 Land, 22: 17-24.

Franki, R.I.B., Fauquet, C.M., Knudson, D.L. and Brown, F. 1991. Classification and nomenclature of viruses $5^{\text {th }}$ Report of Int. Comm. on taxonomy of viruses, suppl. 2.

Hanaa, A.M. Ghomeim, M.A.M. Saad, Hala, A. Salem and Ibrahim, A.A. 2011. Staphylococcus aureus protein "A" as a rapid and sensitive test in comparative with other serological testes for detection of Rift Valley fever antibodies in vaccinated camels Bs. Vet. Med. J. 21(1):67-72

Iman, M. Bastawecy and Saad, M.A.M 2007. Staphylococcus aurous proteinA for improving the performance of transmission Electron Microscopy for rapid diagnosis of lumpy skin disease $9^{\text {th }}$ Sci. Cong., Egyptian Society for cattle disease, Assiut, Egypt

Iman, M. Bastawecy and Saad, M.A.M; Abd El-Samee, A.A and Youssef, H.M 2011. Electron microscopic characterization of Bovine Ephemeral fever virus Journal of American Science 7(12):612-617

Kessler, S.W. 1975. Rapid isolation of antigens from cells with staphylococcal protein-A antibody adsorbent parameters of the interaction of antibody-antigen complex with protein A. J. Immunol. 115(6):1617-1624

Montassier, H.S., Araujo, J.P. and Pnto, A. 1994: Rapid coagglutination test for the detection and typing of foot and mouth disease virus J, Virol. Meth. 50:29-42.

Moussa, A.A., Boulaus, S.M.; El-Sayed, T.E., Fahmy, F.S. and Bohm, H.O. 1974. Typing and subtyping of a strain of FMD virus isolated from Sharquia Province, 1970. J. Egyp. Vet. Med. Ass., 34 (3-4):413-419.

Nielsen, K., Smith, P.W.W, Niceletti, P., Elzer, P., Vigliocco, A., Silva, P., Bermwdez, R., Rentoeria, T., oMreno, F., Ruiz, A., Massengill, C., Muenks, Q., Kenny, K.; Tollerstud, T., Samartino L., Conde, S., Draghi, Ode Benitez, G., Gall, D., Perez, B. and Rojas. 2004: Enzyme immunoassay for the diagnosis of brucellosis: Chimeric Protein Aprotein $\mathrm{G}$ as a common enzyme labeled detection reagent for sera from different animal species: Vet. Microbiol. 101:123-129

OIE 1972. In proceeding of the recommendation of the thirteenth conference of OIE permanent commission on foot and mouth disease off Int. Epiz., pp. 77:1381

OIE Annual Status 2000. Foot and mouth disease, Chapter 2.1.1 in manual of standards for diagnostic tests and vaccine, $4^{\text {th }}$ Ed., Paris, pp. 77-92.

Omnia, F.H., Khodeir, M.H. and Saad, M.A.M. 2015. Preparation and Conjugation of Staphylococcal Protein A "SPA" and streptococcal protein G "SG" with fluorescein isothiocyanate as non-species specific diagnostic kits: Mounofia Vet. J. 2015 under press

Pereira, H.G. 1977. Subtyping of FMDV. Int. Symp. FMD Lyons 1967 Develop. Biol. Standard, 35:167-174. 
Saad, M.A.M., EL- Nakashyly, S., Khodeir, M.H. and Daoud, A.M. 2000. Production and conjugation of staphylococcal protein "A" "SPA" with fluorescein isothirocyanate SPA-FA and with peroxidase 'SPA"ELISA" as a non-species specific diagnostic conjugates: $9^{\text {th }}$ Sci. Cong.
2000, Fac. Vet. Med, Assiut Univ., Egypt

Sharma, S.K. 1981. Foot and mouth disease in sheep and goats: Vet. Res. J. 4(1): $1-21$

Sting, R., Lauerman, L.L. and Blobel, H. 1990: Isolation of protein A and protein $G$ from the bacterial surface Zbl. Bakt. 273:306-312. 